\title{
Analysis of Crustal Structure in the region of Ribeira Belt (between the Provinces of the São Francisco Craton and the Paraná Basin) using Seismological Methods
}

\author{
Diogo Luiz de Oliveira Coelho, Stéphane Drouet, Observatório Nacional, Rio de Janeiro, Brasil
}

Copyright 2014, SBGf - Sociedade Brasileira de Geofísica.

Este texto foi preparado para a apresentação no VI Simpósio Brasileiro de Geofísica, Porto Alegre, 14 a 16 de outubro de 2014. Seu conteúdo foi revisado pelo Comitê Técnico do VI SimBGf, mas não necessariamente representa a opinião da SBGf ou de seus associados. É proibida a reprodução total ou parcial deste material para propésitos comerciais sem prévia autorizaç ão da SBGf.

\section{Abstract}

The working area covers the north of São Paulo, south of Rio de Janeiro and south of Minas Gerais states. Twenty-four broadband seismographic stations swere installed along three profiles, two perpendicular to the coast and one parallel. The distance between the stations is approximately $20 \mathrm{~km}$. The main goal is to determine the crustal structure and image crustal discontinuities in order to help building a geological model of the region under interest. We first checked the level of noise recorded at each stations computing the noise power spectral density, which allowed us to assess the quality of the recordings. We also applied the receiver function method in order to compute the Moho depth at each station. An image of the Moho is build, along the profiles and in $3 \mathrm{D}$, by interpolation of the depths determined at each station. The results show that the Moho gets shallower from the inner continental area towards the coast, from about $\mathbf{4 0} \mathbf{~ k m}$ depth to about $33 \mathrm{~km}$ depth.

\section{Introduction}

The working area is located in the geographic area defined by the coordinates: to the North (21 '19'5" $\mathrm{S} / 45^{\circ} 39^{\prime} 31^{\prime \prime} \mathrm{W}$ and $22^{\circ} 7^{\prime} 59^{\prime \prime} \mathrm{S} / 46^{\circ} 54^{\prime} 23^{\prime \prime} \mathrm{W}$ ) and to the south (23 '8'28" S/48 ${ }^{\circ} 3^{\prime} 28^{\prime \prime}$ and $23^{\circ} 57^{\prime} 33^{\prime \prime} S / 45^{\circ} 28^{\prime} 35^{\prime \prime}$ W), covering the north of São Paulo, South of Rio de Janeiro e South of Minas Gerais. The main cities are : ParatiRJ; Guaratinguetá-SP; Taubaté-SP; Ubatuba-SP; São José dos Campos-SP; Caraguatatuba-SP; São Gonçalo do Sapucaí-MG; Itajubá-MG; Alfenas-MG; Varginha-MG; Pouso Alegre-MG. The total area investigated in this project is approximately $33600 \mathrm{~km}^{2}$.

The geological context of the study area includes the Southeast of Brazil Continental Rift, covered by polycyclic terrains from the south of the Ribeira Belt (Riccomini, 1990) cites in your paper. This Belt is composed of metamorphic rocks, magmatites and granitoids related to Brasiliano Orogenetic Cycle. This geological unit is called Planalto Atlantico by Almeida and Carneiro (1998). The region was also reactivated during past orogenic cycles and the lithological set was intruded by transcorrents thrust systems oriented according to regional trend, with direction ENE to EW (Hasui and Sadowski, 1976).

The main goal of the study is to add information which helps to better understand the geological context of the area under investigation. Using seismological data and methods we intend to map crustal discontinuities. We first compute the noise level at each of the stations in order to perform a rapid quality check of the recordings and then applied the Receiver function method in order to compute the Moho depth at each station. Using interpolation procedure, we generated profiles and maps of the Moho depths which clearly shows that the Moho get thinner from the inner continental area towards the coast, from about 40 $\mathrm{km}$ to about $33 \mathrm{~km}$.

\section{Methodology}

Twenty four broadband seismographic stations were installed along three profiles, two perpendicular to coast and one parallel, as shown in Figure 1. The first profile extends from the station STA01, located near the coast, to STA09. The second profile goes from station STA10 to the north, to station STA16 near the coast. The third profile extends from station STA17, to the west, to station STA24, to the east.
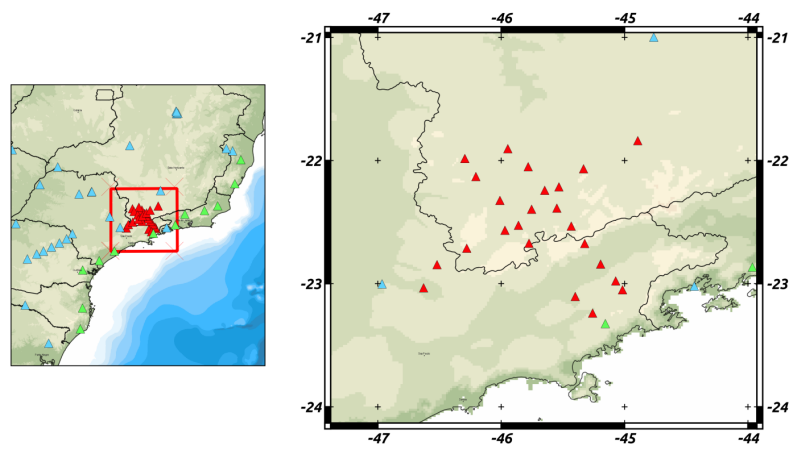

Figure 1: Map of the broadband seismographic stations installed for the project (red triangles). The others triangles are from the Brazilian Seismographic Network (Rede Sismográfica Brasileira

The distance between the stations is approximately $20 \mathrm{~km}$. The seismographs are broadband sensors (Streckeisen STS2 or STS2.5, and Reftek RT151-120s) covering the frequency band $50 \mathrm{~Hz}-100$ seconds. The first two profiles were installed by mid-2012 and the third one by the end of 2012. The stations continuously recorded ground-motion until the end of the project by the end of 2013 .

The distance between the stations is approximately $20 \mathrm{~km}$. The seismographs are broadband sensors (Streckeisen 
STS2 or STS2.5, and Reftek RT151-120s) covering the frequency band $50 \mathrm{~Hz}-100$ seconds. The first two profiles were installed by mid-2012 and the third one by the end of 2012. The stations continuously recorded ground-motion until the end of the project by the end of 2013.

We first estimated the level of noise at each station using the PQLX software. The calculus of noise level is based on the work of McNamara and Buland (2004). The data is splitted in intervals of one hour with $50 \%$ of superposition. Each interval is then further divided in 13 parts with $75 \%$ of superposition to compute the "Power Spectral Density". Then using the results for each of 13 parts "Probability Density Functions" are estimated.

In order to compute the Moho depth and estimate regional crustal thickness, we used the Receiver Function method, that was first introduced by Langston (1977). That method uses the signal of teleseisms, which generate plane waves with quasi-vertical incidence beneath a given station. The P-wave arrival at the Mohorovicic seismic discontinuity, also known as Moho, gives a transmitted P-wave as well as a converted S-wave. The difference in the arrival time of both waves and of some multiples allows us to infer the Moho depth. Figure 2 shows synthetic receiver functions computed by Zhu and Kanamori (2000).

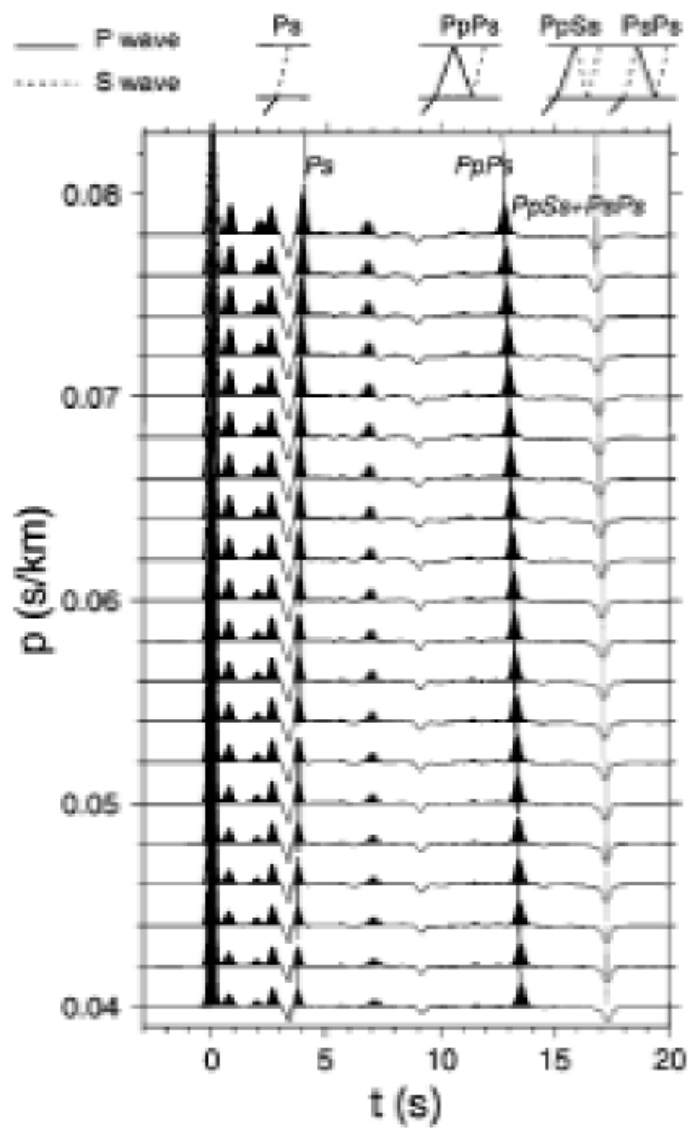

Figure 2: Synthetic Receiver Functions, from (Zhu and Kanamori, 2000)

Earthquakes at distances greater than $95^{\circ}$ do not produce direct P-waves at the stations due to the velocity inversion in the mantle-core boundary. Earthquakes at distance less than 20 degrees generate waves with oblique incidence, and this type of data should be used with caution.

The Receiver Functions are computed using a deconvolution in the time or frequency domain of the radial component by the vertical component. This deconvolution cancels out the similar parts of the signals which are the source and propagation effects until the waves reach the Moho. Consequently, the Receiver Function is sensitive to the crustal structure between the Moho and the surface below the station. The software SAC (Seismic Analysis Code) was used to process and to compute the Receiver Functions.

A robust method to analyse the Receiver Functions is the method of Zhu and Kanamori (2000). Using the average Pwave and S-wave velocities in the crust, the time difference between the P-wave and the converted P-to-S wave can be calculated, as well as the time of multiples, and we can express the Moho depth $\mathrm{H}$ as a function of these arrival times and of the average velocities in the crust.

$$
\begin{aligned}
H & =\frac{t_{P_{s}}}{\sqrt{\frac{1}{v_{s}^{2}}-p^{2}}-\sqrt{s \frac{1}{v_{p}^{2}}-p^{2}}} \\
H & =\frac{t_{P_{p} P_{s}}}{\sqrt{\frac{1}{v_{s}^{2}}-p^{2}}+\sqrt{\frac{1}{v_{p}^{2}}-p^{2}}} \\
H & =\frac{t_{P_{p} S_{s}}+t_{P_{s} P_{s}}}{2 \sqrt{\frac{1}{v_{s}^{2}}-p^{2}}}
\end{aligned}
$$

were tPs is the time arrival of the P-to-S converted wave, and tPpPs, tPpSp, tPsPs the time arrival of the multiples, and $p$ the ray parameter that depends on the location and depth of the event with respect to the station.

Zhu and Kanamori (2000),rather than trying to adjust the whole receiver function, tried to use only the amplitudes at the theoretical arrival times of the P-to-S converted wave and its multiples. Using a grid search for the crustal thickness and the $v_{p} / v_{s}$ ratio, the authors calculate the theoretical arrival times of the converted P-to-S waves and its multiples for each recording. The best combination of crustal thickness and $v_{p} / v_{s}$ ratio is the one that maximizes the amplitude of the stacked receiver functions at the particular times of arrival of the P-to-S converted waves.

To obtain an image of the Moho, the Receiver Functions were stacked for each station and mapped in relation to station position in the profile. In order to test the azimuthal variations of the Receiver Functions, the data are divided in 4 groups according to the azimuth between the earthquake and the station. Most of the recorded events occurred in the West of the South American plate and in Central America. We can note that very few events occur in the Southern Atlantic Ocean. The goal of this separation is to evaluate the possibility of lateral variation of the structure.

\section{Results}

The results from the Figure 3 allow a fast evaluation of the data quality. We observe that some curves are showing some strange behaviour, departing from the upper and lower limits of noise, but are associated with low probabilities (violet curves). Most of the curves are lying well within the intermediary zone, showing good quality 


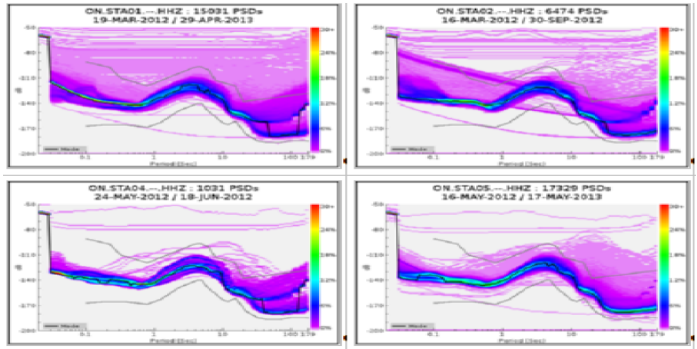

Figure 3: Examples of evaluation of the "Probability of power spectral density" following McNamara and Buland (2004)method, for the vertical component of 4 stations.

data. For some stations, high probabilities appear at short and long period. This is related with diurnal variations. These changes are connected with human activity (short period) and temperature (long period).

\section{Events recorded at STA08}

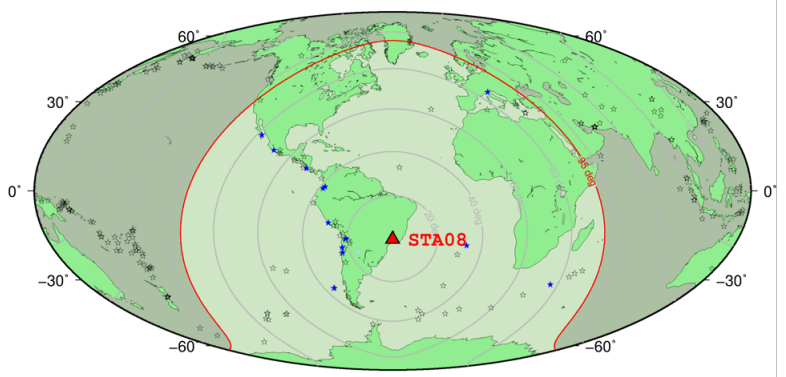

Figure 4: Map of the recorded events at station STA08. The red triangle represents the station and the blue stars the eartquakes used for the Receiver Function analyses, while the grey stars show all the events recorded at STA08.

In general, the noise at short period ( $<1 \mathrm{~s})$ is composed of noise generated by human activities. In the interval between 1 and 15 seconds, the noise is dominated by micro-earthquakes. At longer period ( $>30 \mathrm{~s}$ ) the influence of atmospheric pressure variations and temperature can alter the noise level. In case of temporary installation, the thermic isolation is basic, which carries a high level of long period noise. The earthquakes generate signal of high frequency $(1-10 \mathrm{~Hz})$, in case of local or regional events, while teleseisms are of longer period (10-20 seconds).

Figure 4 shows the recorded events at station STA08. Most of the earthquakes recorded at the stations are events from Andes or Central America. Figure 5 shows a section of Receiver Functions obtained from several events and normalized by the amplitude of the first peak. The first peak is the direct P-wave arrival, the second highest, around 5 seconds, is the $P$ wave converted to $S$ wave at the Moho discontinuity.

The multiples PpPs and PpSs+PsPs have much lower amplitude than the P-to-S conversion. Figure 5 also shows the deconvolution of the transversal component by the vertical component. Assuming a medium, without lateral variation, the deconvolution should be zero. The small

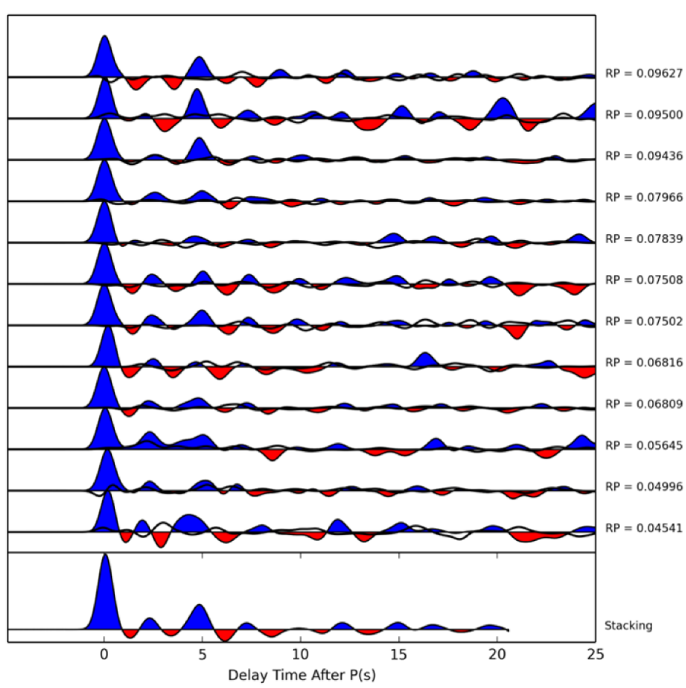

Figure 5: Receiver Functions computed for station STA08 for the different earthquakes and stacked Receiver Function (bottom).

amplitude of the transversal component suggests lateral variations in the properties of medium. To amplify the signal-to-noise ratio of the second peak in the Receiver Functions, a simple stack of all functions was done. Then the data were splitted in four groups according to the azimuth between the event and the station.

We noted in Figure 6 that the Moho depth estimated at STA04 is higher than for the nearby stations. We also identified signals before the Moho, around 2 to 4 seconds, which vary along the profile. This can be related to interfaces with a relatively high contrast of physical property. The negative pulse, red color, may indicate the existence of a low-velocity layer. According with geological setting, we can infer that layer is the Taubate basin, because this basin is located in a rift system, and this explains the subsidence of Mantle.

We calculated the crustal thickness $(H)$ that maximizes the value of real amplitudes of Receiver Function. The best combination of crustal thickness and $v_{p} / v_{s}$ ratio calculated for each station is found in Table 1. The solutions found corroborate with the results from Assumpção et al. (2013b), Assumpção et al. (2013a) and van der Meijde et al. (2013) using data from compilations of works in South America and Brazil. The obtained values for crustal thickness in Table 1 are consistent with the mean measured by Assumpção et al. (2013b), Assumpção et al. (2013a) and van der Meijde et al. (2013), is about $3040 \mathrm{~km}$.

The uncertainties, shown in Table 1, are linked to the quality and the quantity of the Receiver Functions. An important phase is the selection of the best Receiver Functions, because the data quality is preponderant over the quantity. The uncertainty associated with each of the obtained parameters by the Zhu and Kanamori (2000) method are estimated generally by the "bootstrap" method, developed for Efron and Tibshirani (1991). From the original set of Receiver Functions the program generates subsets containing traces randomly selected. These 


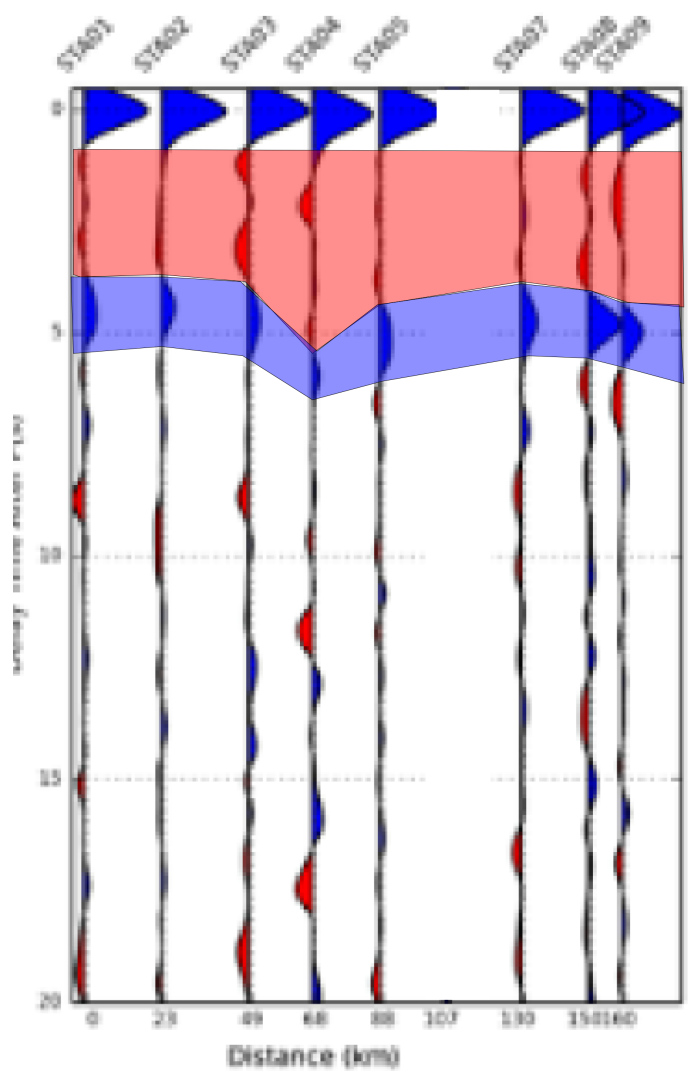

Figure 6: Section of Receiver Functions

method is repeated for each subsets, resulting in a parameter set of $\mathrm{H}$ and $v_{p} / v_{s}$. Mean and standard deviation from the values provide us a mean value and an estimate of the uncertainty associated with the determination. There is no rule for determining the number of subsets that must be generated, the crucial is search a value that makes the estimative stabilize, including uncertainties. In general we use a value between 100 and 200 subsets depending on the amount of traces available during the "bootstrap".

The estimated values of the Moho depth for each station were linearly interpolated to generate a regional map, shown in Figure 7. In order to improve the interpolation, we added data from (Assumpção et al., 2013a). In Figure 7 , we can see the Moho thinning in direction to the east.

\section{Conclusions}

The data analysis indicate some preliminary results about the Moho depth in the region between São Paulo, Minas Gerais and Rio de Janeiro. The Receiver Functions also help to build an image of the crustal structure. The generated images show a thinning trend of the Moho in the East direction, boundary of the continental crust.

\section{Acknowledgments}

The authors wish to express their gratitude to the people who contributed to the Subsal project, to the Observatório Nacional and to the Brazilian Seismographic Network for making data available.

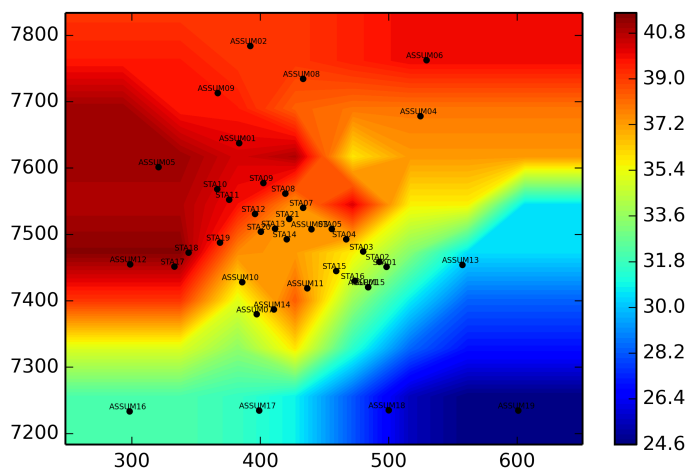

Figure 7: Linear Interpolation of Moho depth computed for each station in addition to more data from (Assumpção et al., 2013a)

\section{References}

Almeida, F. F. M. D., and C. D. R. Carneiro, 1998, Origem e evolução da serra do mar: RBG, 28, 135-150.

Assumpção, M., M. Bianchi, J. Julià, F. L. Dias, G. Sand França, R. Nascimento, S. Drouet, C. G. Pavão, D. F. Albuquerque, and A. E. V. Lopes, 2013a, Crustal thickness map of brazil: Data compilation and main features: Journal of South American Earth Sciences, 43, 74-85.

Assumpção, M., M. Feng, A. Tassara, and J. Julià, 2013b, Models of crustal thickness for south america from seismic refraction, receiver functions and surface wave tomography: Tectonophysics, 609, 82-96.

Efron, B., and R. Tibshirani, 1991, Statistical data analysis in the computer age: Science, 253, 390-395. (PMID: 17746394).

Hasui, Y., and G. R. Sadowski, 1976, Evolução geológica do precambriano na região sudeste do estado de são paulo: Brazilian Journal of Geology, 6, 182-200.

Langston, C. A., 1977, The effect of planar dipping structure on source and receiver responses for constant ray parameter: Bulletin of the Seismological Society of America, 67, 1029-1050.

McNamara, D. E., and R. P. Buland, 2004, Ambient noise levels in the continental united states: Bulletin of the Seismological Society of America, 94, 1517-1527.

Riccomini, C., 1990, O rift continental do sudeste do brasil: text, Universidade de São Paulo. (Tese de Doutorado).

van der Meijde, M., J. Julià, and M. Assumpção, 2013, Gravity derived moho for south america: Tectonophysics, 609, 456-467.

Zhu, L., and H. Kanamori, 2000, Moho depth variation in southern california from teleseismic receiver functions: J. Geophys. Res., 105, 2969-2980. 
Table 1: Table with crustal thickness and $v_{p} / v_{s}$ ratio.

\begin{tabular}{|c|c|c|c|c|c|c|c|c|}
\hline Station & Altitude & Latitude & Longitude & Depth & Uncertainty & Vp/Vs ratio & Uncertainty & Number \\
\hline STA01 & -23.049408 & -45.016808 & 950 & 35.4000 & 3.1246 & 1.7500 & $5.96 \mathrm{E}-002$ & 5 \\
STA02 & -22.977707 & -45.072017 & 886 & 35.6000 & 1.5851 & 1.7200 & $4.28 \mathrm{E}-002$ & 15 \\
STA03 & -22.840839 & -45.194141 & 576 & 35.0000 & 8.3778 & 1.7300 & $9.84 \mathrm{E}-002$ & 19 \\
STA04 & -22.673525 & -45.323162 & 902 & 37.0000 & 7.2112 & 1.7400 & $1.23 \mathrm{E}-001$ & 6 \\
STA05 & -22.5325 & -45.432383 & 1100 & 41.0000 & 6.9241 & 1.6700 & $1.62 \mathrm{E}-001$ & 29 \\
STA06 & -22.386261 & -45.549086 & 931 & 55.2000 & 30.9314 & 1.7900 & $1.05 \mathrm{E}-001$ & 8 \\
STA07 & -22.241667 & -45.647361 & 988 & 38.8000 & 1.7971 & 1.7000 & $4.80 \mathrm{E}-002$ & 24 \\
STA08 & -22.050056 & -45.781374 & 884 & 33.2000 & 6.3031 & 1.8500 & $1.33 \mathrm{E}-001$ & 22 \\
STA09 & -21.903929 & -45.946331 & 1045 & 42.6000 & 4.3086 & 1.6800 & $8.77 \mathrm{E}-002$ & 30 \\
STA10 & -21.98335 & -46.29471 & 1135 & 38.8000 & 3.9148 & 1.7500 & $7.05 \mathrm{E}-002$ & 5 \\
STA11 & -22.12999 & -46.20536 & 1455 & 41.0000 & 4.2658 & 1.7100 & $9.04 \mathrm{E}-002$ & 11 \\
STA12 & -22.32379 & -46.01047 & 890 & 37.4000 & 0.6134 & 1.7700 & $1.52 \mathrm{E}-002$ & 25 \\
STA13 & -22.52571 & -45.86029 & 918 & 35.8000 & 3.2668 & 1.7800 & $7.67 \mathrm{E}-002$ & 13 \\
STA14 & -22.67147 & -45.77467 & 974 & 38.0000 & 2.9979 & 1.8000 & $7.40 \mathrm{E}-002$ & 12 \\
STA15 & -23.10378 & -45.39983 & 895 & 35.8000 & 0.8721 & 1.7400 & $3.26 \mathrm{E}-002$ & 6 \\
STA16 & -23.2387 & -45.25919 & 906 & 32.2000 & 4.1659 & 1.8000 & $1.06 \mathrm{E}-001$ & 7 \\
STA17 & -23.0337 & -46.62914 & 776 & 37.8000 & 1.5258 & 1.6900 & $4.39 \mathrm{E}-002$ & 6 \\
STA18 & -22.84539 & -46.52033 & 957 & 41.0000 & 8.0172 & 1.7200 & $1.32 \mathrm{E}-001$ & 5 \\
STA19 & -22.71192 & -46.27943 & 1413 & 39.0000 & 2.5130 & 1.7500 & $6.23 \mathrm{E}-002$ & 18 \\
STA20 & -22.56621 & -45.96951 & 908 & 38.2000 & 4.1389 & 1.7500 & $8.20 \mathrm{E}-002$ & 11 \\
STA21 & -22.39548 & -45.75364 & 957 & 39.0000 & 4.8590 & 1.7200 & $1.07 \mathrm{E}-001$ & 9 \\
\hline
\end{tabular}

